\title{
Os desafios da Alfabetização Científica na fala de um grupo de professores dos anos iniciais
}

\author{
The challenges of the Scientific Literacy in the speech of a group \\ of teachers of the initial years
}

Graziela Ferreira de Souzaㄹ; Nilcéia Aparecida Maciel Pinheiro ${ }^{1}$

\section{RESUMO}

Este estudo apresenta uma reflexão sobre os desafios da Alfabetização Científica, identificados nas falas de professores dos anos iniciais do ensino fundamental. Com foco na investigação das concepções dos professores sobre o ensino de ciências e a alfabetização científica, o objetivo deste estudo foi delinear os desafios e práticas pedagógicas desenvolvidos nessa perspectiva. Como procedimento metodológico foi aplicado um questionário a 15 professores atuantes na rede municipal de ensino de Ponta Grossa - PR, que se encontravam em formação continuada para o ensino de ciências oferecida pela instituição. A análise qualitativa, de natureza interpretativa das respostas demonstrou consonância com a literatura da área, revelando que há limitações e desafios enfrentados pelos professores no exercício de suas atividades pedagógicas ligadas ao ensino de ciências. Os entraves identificados indicam que diante de tais dificuldades torna-se necessário ampliar estudos e formação de professores em nível inicial e continuada, para o desenvolvimento da Alfabetização Científica desde as etapas iniciais do ensino fundamental.

Palavras-chave: Alfabetização Científica; Ensino de Ciências; Ensino Fundamental.

\begin{abstract}
This study presents a reflection on the challenges of the Scientific Literacy, identified in the speeches of teachers of the initial years of elementary education. The objective of this study was to outline the challenges and pedagogical practices developed in this perspective with focus on the investigation of teachers' conceptions of the early years on science teaching and scientific literacy. The methodological procedure was the application of a questionnaire to 15 teachers working in the municipal education network of Ponta Grossa - PR, who were in continuous formation for the science teaching offered by the institution. The qualitative analysis, with an interpretative nature of the answers, was in agreement with the literature of the area, revealing that there are limitations and challenges faced by teachers in the exercise of their pedagogical activities related to the teaching of sciences. The obstacles identified indicate that in the face of such difficulties it is necessary to expand studies and teacher training at an initial level and in a continuous way, as a possibility for the development of Scientific Literacy from the initial stages of elementary education.
\end{abstract}

Keywords: Scientific Literacy; Science Teaching; Elementary Education.

\footnotetext{
${ }^{1}$ UFTPR - Universidade Tecnológica Federal do Paraná, Ponta Grossa/PR - Brasil.
} 


\section{INTRODUÇÃO}

As implicações de uma sociedade desenvolvida científica e tecnologicamente indicam a necessidade da construção de uma democratização de saberes que envolvem a formação de cada cidadão em espaços formais e informais de ensino.

A Alfabetização Científica está ligada diretamente a formação dos alunos para a vida em sociedade. Nesta abordagem as práticas educacionais desenvolvem-se dialogicamente, através da investigação, reflexão e interdisciplinaridade, contribuindo para a compreensão e tomada de decisões diante dos avanços científicos e tecnológicos.

O desenvolvimento de uma cultura científica e a alfabetização nesta área traz ao ensino uma ruptura aos padrões de ensino tecnicistas, que versam pela valorização da memorização e reprodução de conceitos e generalizações. Em oposição a esta abordagem entende-se que alfabetizar cientificamente está relacionado a emancipação do sujeito, onde há o desenvolvimento do protagonismo do aluno diante da sua aprendizagem.

No espaço escolar, esta perspectiva gera desafios pedagógicos que compreendem a capacidade de formação de cidadãos cada vez mais aptos para intervir e compreender o mundo que os rodeia de forma consciente e responsável.

Este aspecto pressupõe novas abordagens ao ensino, sob um enfoque reflexivo diante da ciência e tecnologia, contribuindo para a Alfabetização Científica dos educandos. Para tanto, é necessário que as práticas pedagógicas e concepções dos professores estejam em consonância com essa perspectiva.

Assim, alfabetizar cientificamente está relacionado ao desenvolvimento do espírito científico, compreensão dos fenômenos naturais, suas inter-relações com os seres humanos, o meio ambiente e a tecnologia. Isso possibilita desvendar o mundo e compreendê-lo como uma unidade, contribuindo para uma perspectiva de formação interdisciplinar.

Neste sentido, este estudo problematiza aspectos relacionados ao ensino de ciências nos anos iniciais sob a ótica da Alfabetização Científica, investigando as concepções de professores sobre a área e os principais entraves para a ocorrência dessa abordagem nesta etapa da educação básica diante da narrativa dos professores investigados.

\section{ALFABETIZAÇÃo CIENTÍFICA}

A Alfabetização Científica pode ser entendida como uma perspectiva de abordagem educacional, cujos objetivos estão ligados ao desenvolvimento de uma sociedade capaz de atuar de forma crítica, reflexiva e responsável diante das situações ligadas a ciência e tecnologia que emergem ao seu redor. Para Lorenzetti e Delizoicov (2001, p.8-9), a Alfabetização Científica é entendida "[...] como o processo pelo qual a linguagem das Ciências Naturais adquire significados, constituindo-se um meio para o indivíduo ampliar o seu universo de conhecimento, a sua cultura, como cidadão inserido na sociedade".

Ao compreendê-la como uma linguagem, o desenvolvimento de uma cultura científica ganha espaço e maior importância dentro dos ambientes de ensino. Entende-se que é necessário alfabetizar cientificamente os estudantes, pois nas palavras de Chassot (2003, p.91) "ser alfabetizado 
cientificamente é saber ler a linguagem em que está escrita a natureza. É um analfabeto científico aquele incapaz de uma leitura do universo".

Desta forma, faz-se necessário o desenvolvimento de processos de ensino que preparem os alunos para a compreensão deste universo, o que exige uma modificação nos currículos escolares e na formação docente, assim como ressalta Cachapuz et al. (2005):

Para uma renovação no Ensino de Ciências precisamos não só de uma renovação epistemológica dos professores, mas que essa venha acompanhada por uma renovação didático-metodológica de suas aulas (p.10).

Estas mudanças nas abordagens de ensino colocam-se em concordância com a fala de Delizoicov, Angotti e Pernambuco (2009, p. 34), ao afirmarem que "o trabalho docente precisa ser direcionado para a sua apropriação crítica pelos alunos, de modo que efetivamente se incorpore no universo das representações sociais e se constitua como cultura".

Assim, a necessidade de mudanças de práticas para o desenvolvimento da Alfabetização Científica torna-se evidente ao ensino de ciências em todos os segmentos de ensino. Nesse sentido, pretendese que a Alfabetização Científica possa ser desenvolvida deste os primeiros anos da educação básica, conforme ressalta Vale (2009, p.14):

Uma Educação Científica deverá começar desde tenra idade, desde a pré-escola, cultivando a curiosidade da criança corporificada no insistente por quê o infantil que, em mais de uma vez, tem colocado muito pai e muito educador em situação difícil. Entendo que a criança nasce com o desejo de conhecer o mundo e que a escola "mata" a natural curiosidade infantil com um ensino pobre e defasado muito aquém das necessidades e interesses dos jovens.

A fala de Vale (2009) complementa o entendimento de Lorenzetti e Delizoicov (2001) os quais consideram que a Alfabetização Científica é uma atividade a ser trabalhada em todo o âmbito educacional, desde os anos iniciais mesmo antes da criança saber ler e escrever. Ao longo do processo de escolarização, essas práticas formativas ampliam-se de modo a construir um pensamento científico e uma postura crítica como cidadão diante da ciência e tecnologia.

No entanto essa perspectiva exige que as práticas pedagógicas estejam de acordo com a abordagem da Alfabetização Científica, proporcionando o desenvolvimento de estratégias de significação social das aprendizagens (BRITO, 2014).

Deste modo, compreende-se que a Alfabetização Científica não está relacionada a levar os alunos apenas a conhecerem sobre ciência e manejar artefatos tecnológicos. Ela compreende um processo mais amplo, no qual há o desenvolvimento de atitudes de investigação, reflexão e posicionamento crítico que são características relevantes para o desenvolvimento da cidadania (RODRIGUES, 2010).

É inegável a contribuição que a ciência e a tecnologia trouxeram nos últimos anos. Porém, apesar desta constatação, não podemos confiar excessivamente nelas, tornando-nos cegos pelo conforto que nos proporcionam cotidianamente seus aparatos e dispositivos técnicos. Isso pode resultar perigoso porque, nesta anestesia que o deslumbramento da modernidade tecnológica nos oferece, podemos nos esquecer que a ciência e a tecnologia incorporam questões sociais, éticas e políticas (BAZZO, 1998, p. 142). 
Desenvolver essas habilidades permite que os alunos construam um processo de aprendizagem capaz de relacionar conceitos e conteúdos de várias áreas do saber à suas implicações sociais, culturais, políticas, econômicas e tecnológicas.

Assim, a contribuição da alfabetização científica está ligada à formação de um cidadão capaz de ser sujeito de transformação em sociedade. Como meio para a efetivação desta proposta, tem-se no ensino de ciências as ferramentas necessárias para o desenvolvimento de habilidades que tornem os educandos capazes de contribuir para a tomada de decisões diante da produção científica e tecnológica.

\section{O ENSINO DE CIÊNCIAS NOS ANOS INICIAIS}

Ao longo das últimas décadas o ensino de Ciências Naturais tem se desenvolvido sob diferentes propostas educacionais e metodológicas, cujos objetivos pautam-se na de que o ensino de Ciências está diretamente relacionado à formação do cidadão.

Sob esse aspecto, Viecheneski e Carletto (2013, p. 2) ressaltam que o ensino de ciências "orienta-se para a promoção da cidadania, com vistas ao desenvolvimento dos sujeitos enquanto cidadãos ativos, consumidores e usuários responsáveis da tecnologia existente".

O ensino de ciências nos anos iniciais do ensino fundamental visa construir os primeiros significados do mundo científico e colaborar para a compreensão dos fenômenos da natureza. Isso permite que ao longo do processo educacional o aprendiz sistematize estes conhecimentos, construindo conceitos e ressignificando-os em sua prática.

Encontramos amparo a isso, nos PCN ao apresentarem que:

O ensino de Ciências Naturais também é espaço privilegiado em que as diferentes explicações sobre o mundo, os fenômenos da natureza e as transformações produzidas pelo homem podem ser expostos e comparados. É espaço de expressão das explicações espontâneas dos alunos e daquelas oriundas de vários sistemas explicativos (BRASIL, 1997, p. 22).

Como caracterizado nos documentos, o ensino de ciências durante todas as etapas do ensino fundamental deverá propiciar conhecimentos e oportunidades de desenvolvimento de habilidades para compreensão dos fenômenos e transformações da sociedade, onde o aluno possa tomar posição e intervir em sua realidade (LORENZETTI, 2000). Neste sentido, esse mesmo autor destaca que:

A prática pedagógica deverá oportunizar aos educandos, para além do exercício da verbalização de ideias, discutir as causas dos fenômenos, estabelecendo relações causais, entendendo os mecanismos dos processos que estão estudando e analisando, onde e como aquele conhecimento apresentado em sala de aula está presente em sua vida e, sempre que possível, relacioná-lo com as implicações deste conhecimento com a sociedade como um todo (LORENZETTI, 2000, p. 24).

Segundo Rodrigues (2010, p. 22) o fato de "apropriar conceitos científicos não significa captar conteúdos, mas trata-se de um processo complexo que envolve a organização do pensamento e a interação deste com a realidade". Desse modo, o processo iniciado nos primeiros anos do ensino fundamental tem como fundamento a compreensão dos fenômenos naturais, mas também aproxima 
os educandos da ciência, uma vez que o conhecimento científico não deve ser apenas transmitido, mas sim construído pelo aprendiz.

As possibilidades de colaborar para o desenvolvimento da posição crítica e reflexiva dos alunos também são destacadas por Lorenzetti (2000, p. 32) ao afirmar que "nas séries iniciais a criança defronta-se com o conhecimento científico e sua compreensão dependerá da concepção de Ciência e de Educação que baliza a prática pedagógica".

Embora nos anos iniciais os educandos ainda não sejam capazes de utilizarem generalizações e abstrações, na medida em que se apropriam dos conceitos científicos, tornam-se capazes de avançar nas compreensões de sua realidade sociocultural.

Boss et al. (2012) afirmam que o trabalho com ciências naturais é possível para nos anos iniciais, pois pode contribuir para que o aluno compreenda conceitos e construa saberes que o auxiliarão na aprendizagem dos conceitos científicos na etapa final do ensino fundamental.

Vale também relembrar o que destaca de Rosa, Perez e Drum (2007, p. 362) sobre o ensino de ciências nos anos iniciais:

Ao ensinar ciências às crianças, não devemos nos preocupar com a precisão e a sistematização do conhecimento em níveis da rigorosidade do mundo científico, já que essas crianças evoluirão de modo a reconstruir seus conceitos e significados sobre os fenômenos estudados. O fundamental no processo é a criança estar em contato com a ciência, não remetendo essa tarefa a níveis escolares mais adiantados.

Considerando isso, entende-se que proporcionar o contato com conceitos científicos desde os primeiros anos do ensino fundamental é promover a Alfabetização Científica e Tecnológica e o desenvolvimento das capacidades de observação, investigação e discussão de ideias. Para tanto, as abordagens metodológicas devem estar alinhadas a esses propósitos a fim de contribuir com esse processo formativo.

\section{PROCEDIMENTOS METODOLÓGICOS}

De modo a identificar a ocorrência da Alfabetização Científica no contexto dos anos iniciais do ensino fundamental, investigou-se junto a um grupo de professores as concepções dos mesmos sobre o ensino de Ciências.

A coleta de dados junto aos professores ocorreu por meio de um questionário, aplicado a um grupo de 15 docentes dos anos iniciais, que participavam de uma formação continuada para o ensino de ciências, promovida pela rede municipal de ensino da cidade de Ponta Grossa-PR.

Optou-se por uma estrutura com questões abertas para que os participantes pudessem descrever aquilo que mais se adequava ao seu trabalho e sua formação. Richardson (2008) recomenda o uso de questões abertas para essa etapa, pois, de acordo com o autor, isso oportunizará ao pesquisador um aprofundamento dos conhecimentos em relação ao tema da pesquisa, assim como ressalta Severino (2008, p.125), ao afirmar que nas questões abertas "o sujeito pode elaborar as respostas, com suas próprias palavras, a partir de sua elaboração pessoal". 
$\mathrm{O}$ instrumento de investigação levantou incialmente o perfil dos professores e questionou suas concepções e compreensões sobre o ensino de ciências naturais e o desenvolvimento da alfabetização científica.

Para análise deste material, foram elencadas três categorias de acordo com as questões do instrumento e também com as respostas obtidas, cujas análises serão apresentadas na próxima seção.

\section{RESULTADOS E DISCUSSÃO}

Entender as concepções dos professores sobre o ensino de ciências coloca-se para esta pesquisa como uma possibilidade de delinear um panorama da atuação dos docentes em relação ao ensino, de modo a entender obstáculos ou indicativos da ocorrência da Alfabetização Científica nos anos iniciais. Segundo Rosa et al. (2007):

Para a Alfabetização Científica dos estudantes, o professor, principalmente, nas séries iniciais, passa a ser o centro do processo, suas concepções sobre a importância dos conhecimentos de física para o processo formativo de seus alunos, bem como a compreensão que ele tem do processo ensino-aprendizagem serão determinantes para que a ciência seja contemplada no contexto escolar como cultura necessária à vida dos estudantes, independentemente da opção profissional que assumirão no decorrer de seus estudos. (p.2)

Neste sentido a racionalidade do instrumento aplicado aos professores baseou-se em três categorias: (a) estabelecer um perfil de formação e atuação dos professores; (b) compreender as concepções de ciências e identificar práticas educacionais e (c) os desafios enfrentados no ensino de ciências.

\subsection{Perfil dos participantes}

Apresentam-se nas figuras a seguir o perfil dos professores participantes do estudo de acordo com sua faixa etária, tempo de atuação, nível e área de formação. Ao levantar aspectos buscamos compor uma análise diagnóstica dos profissionais, relacionando-as à concepções de ensino dos mesmos, identificadas ao longo da pesquisa.

A Figura 1 apresenta o tempo de atuação na carreira docente. Os dados desta questão foram analisados segundo a classificação de Huberman (2000) que distingue cinco fases que marcam o processo de evolução da profissão: a entrada na carreira (de 1 a 3 anos de profissão), a estabilização (de 4 a 6 anos), a experimentação ou diversificação (de 7 a 25 anos), a serenidade ou distanciamento afetivo (25 a 35 anos) e a preparação para a aposentadoria (35 a 40 anos de profissão).

De acordo com esta categorização, a maior parte (60 \%) dos professores atuantes na instituição pesquisada encontra-se na fase de experimentação ou diversificação, que compreende o período entre 7 e 25 anos de atuação docente e é marcado pelas buscas de desafios.

Segundo Huberman (2000) este é o período em que o professor experimenta novas práticas e diversifica métodos de ensino, tornando-se mais crítico. Porém pode também se caracterizar, como uma fase de questionamentos, gerando uma crise, seja pela monotonia do cotidiano da sala de aula, seja por um desencanto causado por fracassos em suas experiências ou por reformas estruturais. 
Não se trata, portanto, de um ciclo homogêneo, no qual seja fácil caracterizar o pensamento e a conduta profissional do docente.

Figura 1: Tempo de atuação docente, classificação segundo Huberman (2000)

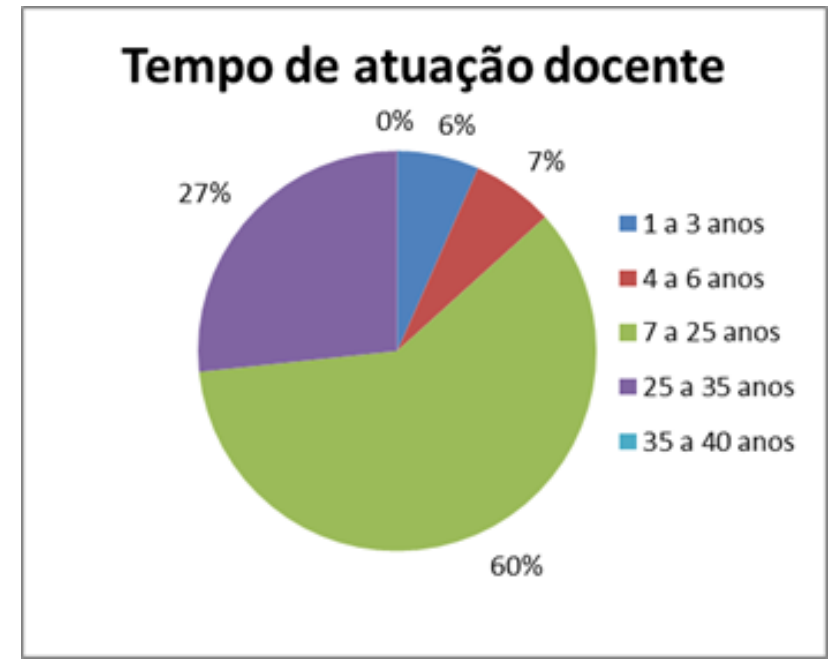

Fonte: Dados da pesquisa

Essa faixa correspondente ao tempo de atuação docente também justifica o nível de formação dos profissionais. Conforme figura 2, observa-se que a maioria dos profissionais possui formação em nível de pós-graduação, reiterando o que afirma a classificação de Huberman sobre a busca pela capacitação profissional dos mesmos.

Figura 2: Nível de formação dos docentes

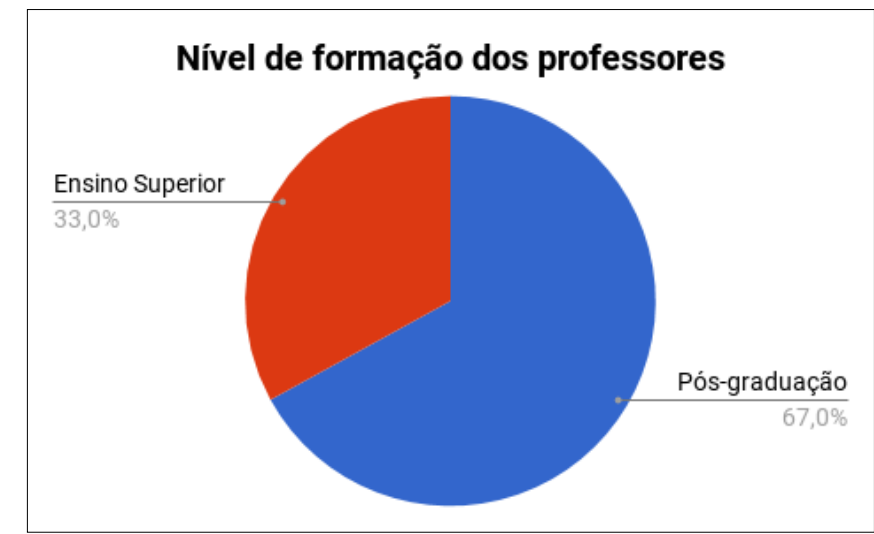

Fonte: Dados da pesquisa

Em relação a área de formação dos profissionais, dos 15 professores participantes apenas um é licenciado em geografia, os demais são todos pedagogos, atuantes no segmento dos anos iniciais como professores polivalentes.

O perfil dos professores traçado nessa análise permitiu a compreensão das práticas realizadas em sala de aula. As observações dessa etapa da pesquisa complementaram-se com a fala dos professores em relação ao ensino de ciências que se apresentam descritas a seguir.

\subsection{Concepções sobre o ensino de ciências}

Para identificar as concepções dos professores da instituição pesquisada, realizaram-se questionamentos acerca do entendimento do que é ciência e das práticas pedagógicas relacionadas no ensino de ciências naturais. 
Em relação ao entendimento do que é ciência (Q1), nota-se que o questionamento aberto, permitiu um grande leque de conceitos sobre o tema, conforme se observa a seguir:

"Tudo o que procura comprovação através de experimentos e pesquisa" (Professor 3) "É um vasto campo de estudos. É o conhecimento sobre o universo e tudo o que se encontra ao seu redor" (Professor 7)

"É muito abrangente, envolve vários ramos: humanas, tecnológicas, novas descobertas e novos conhecimentos" (Professor 8)

"Estudo sistematizado em determinada área" (Professor 11)

"Conhecimentos comprovados cientificamente" (Professor 14)

"É a disciplina que estuda o ambiente natural e os seres vivos e suas relações" (Professor 15)

Assim, verifica-se que o entendimento sobre o que é ciência versa sobre uma concepção da mesma como área de saber, disciplina escolar e também há referência da mesma como método científico. Contudo, não há uma definição mais correta ou coerente a se apontar nesse questionamento.

As respostas do grupo permitiram-nos identificar que de modo geral há compreensão da ciência como uma construção humana, pautada em métodos e sistematização de estudos que busca compreender as relações do ser humano e do ambiente.

Há uma unanimidade no reconhecimento da ciência como fundamental ao processo de escolarização na etapa inicial do Ensino Fundamental, ao responderem sobre a importância do ensino de ciências (Q2).

Estas considerações justificam-se nas falas dos professores ao entenderem que o ensino de ciências "estimula a curiosidade, a pesquisa e o desenvolvimento do pensamento nos alunos, quesitos fundamentais ao homem moderno" (Professor 2).

A fala do professor 2 demonstra coerência com a literatura, sobretudo no que apontam Rosa, Perez e Drum (2007, p. 361) ao afirmar que "o papel da escola desde o momento da chegada da criança deveria ser o de favorecer a sua curiosidade e seu poder investigativo, alimentando-o e intensificandoo a cada nova etapa de escolarização".

Isso revela proximidade com os objetivos da alfabetização científica, sobretudo ao aspecto que valoriza a ciência como linguagem e habilidade necessária ao homem moderno. As respostas a esta questão também foram ao encontro do que explicitam Lorenzetti e Delizoicov (2001) ao afirmarem que o desenvolvimento de uma alfabetização científica está relacionado as necessidades de sobrevivência do homem, por entender que as relações estabelecidas entre a a Ciência, a Tecnologia e seus artefatos estão intensamente ligadas ao cotidiano da sociedade.

A terceira questão investigada (Q3), tinha como foco a possibilidade do ensino de ciências desenvolver o conhecimento científico. Buscava-se compreender as concepções dos profissionais ligadas à alfabetização científica dos alunos nos anos iniciais.

Neste sentido, os professores pesquisados identificam a importância do conhecimento científico e o reconhecem como uma série de procedimentos ligados à pesquisa, experimentação, interdisciplinaridade, reflexão e valorização da curiosidade e interesse da criança. 
Tendo em vista que os participantes atuam em diferentes etapas do ensino fundamental $\left(1^{\circ}\right.$ ao $5^{\circ}$ ano), verifica-se que os mesmos reconhecem que é possível abordar conteúdos da esfera científica em todo o ensino fundamental, de acordo com os processos cognitivos possíveis para cada faixa etária.

Sobre esse aspecto há consenso na literatura (CARVALHO et. Al, 1998; LORENZETTI, 2000; ROSA, PEREZ, DRUM, 2007) que mesmo não estando apta a generalizações e abstrações que exigem maior domínio e desenvolvimento cognitivo, a criança dos anos iniciais do ensino fundamental está inserida em um meio científico. O contato de dá naturalmente e por meio da curiosidade intrínseca da idade pode ser explorada, ampliando a visão de ciência e sobre os fenômenos que a cercam.

Embora seja possível identificar entre o grupo pesquisado o reconhecimento das possibilidades que 0 ensino de ciência pode proporcionar para a Alfabetização Científica, também identificam-se algumas dificuldades e desafios que são observados entre as falas dos educadores.

Outro ponto a destacar na pesquisa realizada foi a concepção dos professores em relação aos conhecimentos relacionados às Ciências Naturais. Ao responderem o questionamento sobre "Quais as "ciências" fazem parte do grupo das ciências naturais?" (Q4) as respostas foram bastante desencontradas, conforme é possível observar no quadro abaixo:

Quadro 1: Respostas dos professores ao questionamento 4 Quais as ciências fazem parte do grupo das Ciências Naturais?

\begin{tabular}{|c|c|}
\hline $\begin{array}{c}\text { Índice } \\
\text { Temática/Disciplina/Conteúdo }\end{array}$ & $\begin{array}{c}\text { Indicador } \\
\text { Número de } \\
\text { menções }\end{array}$ \\
\hline Biologia & 6 \\
\hline Natureza (meio ambiente) & 5 \\
\hline Astronomia & 4 \\
\hline Física & 3 \\
\hline Geologia & 3 \\
\hline Química & 3 \\
\hline Saúde & 3 \\
\hline Biogeografia & 2 \\
\hline Seres Humanos & 2 \\
\hline Anatomia & 1 \\
\hline Botânica & 1 \\
\hline Botânica & 1 \\
\hline Corpo humano & 1 \\
\hline Corpos celestes & 1 \\
\hline Fisiologia & 1 \\
\hline Medicina & 1 \\
\hline Recursos Tecnológicos & 1 \\
\hline
\end{tabular}

Fonte: Dados da pesquisa

As percepções dos professores acerca da área encontram-se pulverizadas, porém compreendem o eixo balizado por um dos documentos que norteiam o processo de ensino.

Para o ensino de Ciências Naturais é necessária a construção de uma estrutura geral da área que favoreça a aprendizagem significativa do conhecimento historicamente 
acumulado e a formação de uma concepção de Ciência, suas relações com a Tecnologia e com a Sociedade (BRASIL, 1997, p.27).

A fala dos professores apresenta-se coerente com os documentos legais para o ensino fundamental. De acordo com os PCN do ensino fundamental, o currículo de ciências se organiza em quatro blocos temáticos: Ambiente; Ser humano e saúde; Recursos tecnológicos; e Terra e Universo, além disso os PCN ainda afirmam que uma importância e variedade de conteúdos a ser considerada pelo professor em seu planejamento tais como Astronomia, Biologia, Física, Geociências e a Química, assim como dos conhecimentos tecnológicos (BRASIL, 1997).

Neste sentido, pode-se compreender que embora diversas, as respostas dos professores investigados demonstram relação com os blocos temáticos e eixos presentes nos referenciais para o ensino de ciências, compreendendo-o como um componente curricular com amplitude de objetos de investigação.

\subsection{Práticas pedagógicas desenvolvidas nos anos iniciais}

Quando questionados por formação recebida na área de ciências (Q5), os professores responderam conforme figura abaixo:

Figura 3: Formação na área de ciências naturais

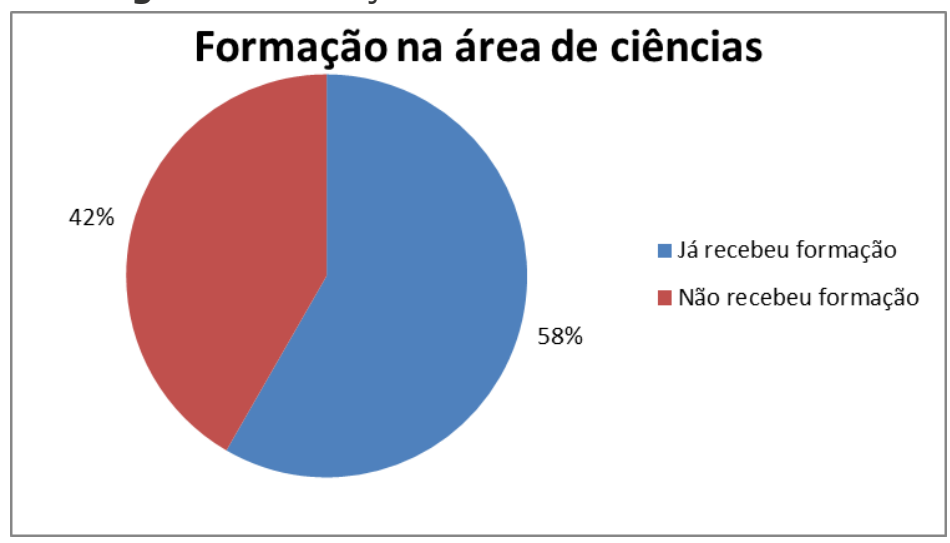

Fonte: Dados da pesquisa

Como visto, a maior parte dos professores afirma ter recebido formação na área de ciências, porém, como observado anteriormente os professores do segmento são polivalentes, ou seja, desenvolvem aulas de várias disciplinas para os alunos do Ensino Fundamental.

Esta polivalência do educador dos anos iniciais apresenta certa limitação ao desenvolvimento do ensino de ciência, pois os professores dessa etapa da escolarização, polivalentes e generalistas, muitas vezes, encontram dificuldades para ensinar Ciências devido a sua formação com pouca ênfase nessa área.

Segundo pesquisa da área, na maioria das vezes há maior predominância e ênfase na alfabetização e o ensino de matemática por julgá-los mais relevantes (DELIZOICOV; ANGOTTI, 2000; ROSA et al., 2007).

Este também foi um dos aspectos identificados nas respostas dos entrevistados, ao afirmarem que nos anos iniciais há mais atenção aos currículos de matemática e língua portuguesa do que para com o currículo de ciências. Isso verifica-se, por exemplo, na fala de um dos professores: "Acredito que o 
foco nos primeiros anos seja destinado a alfabetização e ao domínio das primeiras operações matemáticas, sendo que o ensino de ciências fica em segundo plano"(Professor 1).

Entende-se também na fala dos professores a necessidade de aprofundamento e mais conhecimento para o desenvolvimento das práticas educacionais ligadas ao ensino de ciências. Ao serem questionados sobre a importância de formação nesta área (Q6) os professores sinalizaram que:

"É importante para que os professores sintam-se mais seguros..." (Professor 1)

"Muito importante, pois é necessário ter domínio do conteúdo e descobrir novas formas de transmitir o conhecimento" (Professor 4)

"[...] são conteúdos que muitas vezes podem ser trabalhados na prática com alunos e, como não é trabalhado muito bem na formação acadêmica, os professores não conseguem administrar uma aula instigante" (Professor 9)

Diante destas afirmações, ao responderem sobre as dificuldades enfrentadas no ensino de ciências (Q7) todos os professores entrevistados apontaram que mesmo sabendo sobre a importância da ciência, não a contemplam com mais evidência em sala de aula porque se sentem inseguros para discutir e realizar um trabalho sistemático com os alunos dentro do eixo das ciências naturais.

Em pesquisa realizada por Rosa, Perez e Drum (2007) dificuldades semelhantes foram observados, identificando o aspecto da "inércia pedagógica" que se observa na prática docente, decorrente ora da falta de interesse na buscar por capacitação, ora pelas condições de trabalho que não qualificação docente.

As dificuldades apresentadas pelos professores para o trabalho com o ensino de ciências vão além de sua formação. Elas estão ligadas também a falta de material, ausência de estrutura e apoio pedagógico para realização e atividades que sejam capazes de desenvolver a reflexão, investigação e confronto de ideias.

Segundo Longhini (2008), são preocupantes as dificuldades que os docentes possuem. Em pesquisa realizada por este autor junto a um curso de Pedagogia, o livro didático foi apontado como recurso de maior destaque e suporte a prática dos professores.

Este elemento também foi identificado na pesquisa realizada com os professores da rede municipal de ensino pesquisada, os quais afirmaram encontrar no livro didático o suporte necessário para o desenvolvimento das práticas relacionadas à formação de conceito e investigação em ciências (Q8).

Para que se possa efetivar a Alfabetização Científica nos anos iniciais é preciso que o professor seja capaz de se desvencilhar e confrontar saberes, usando o livro didático como um elemento, entre os vários materiais de consulta e construção pedagógica. Sobre as principais desvantagens do uso exclusivo do livro didático nas aulas de ciências Viecheneski, Lorenzetti e Carletto (2012, p. 862) afirmam que:

Essa prática traz consequências, como o distanciamento entre a vida social dos alunos e os conteúdos escolares, uma vez que esse tipo de trabalho não leva em consideração a realidade do aluno, nem seus conhecimentos prévios, não propicia o questionamento e a reflexão. 
Apenas quatro professores (27\%) apontaram nas respostas aos questionários que utilizam além do livro didático o uso de experiências, situações do cotidiano, vídeos e materiais retirados da internet como ferramentas de apoio pedagógico à prática do ensino de ciências.

De acordo com Rosa, Perez e Drum (2007) esse aspecto tende a negligenciar a alfabetização científica do aluno, pois tende a formatar o ensino de ciências na reprodução e memorização de conceitos.

Entende-se segundo esses dados que o aporte para o desenvolvimento está pautado, em sua maioria, aos livros didáticos adotados pelo segmento de ensino, promovendo um ensino basicamente teórico, memorístico e de reprodução de conceitos científicos.

Assim sendo, a reflexão levantada por esta pesquisa evidencia que a ocorrência da Alfabetização Científica nas etapas iniciais do ensino fundamental ainda precisa de mais estudos, mudanças nos currículos de ensino e também de formação de professores.

Neste sentido, compreende-se a importância de trazer para o contexto educacional discussões pertinentes aos avanços da ciência e da tecnologia de modo a promover práticas de ensino de ciências que sejam capazes de aproximar os alunos de uma dimensão reflexiva e científica.

\section{CONSIDERAÇÕES FINAIS}

A importância do desenvolvimento da Alfabetização Científica encontra-se ligada ao processo pelo qual se oportuniza ampliação da cultura através do trabalho com o conhecimento científico numa perspectiva dialógica e investigativa.

Fica claro que dentro desta abordagem há maior destaque para as relações que são estabelecidas entre o conhecimento científico e suas implicações sociais, rompendo com o acúmulo de conceitos e memorização ainda evidentes nos processos de ensino da Educação Básica.

A pesquisa realizada identificou a compreensão desses aspectos por parte dos professores, porém apontou que no ensino de ciências a efetivação da Alfabetização Científica ainda precisa superar alguns desafios e entraves.

Entende-se, de acordo com a fala dos professores, que há necessidade de ampliar não somente estudos nesta área, mas capacitação dos docentes de forma inicial e continuada, para que possam de fato realizar práticas pedagógicas voltadas para o desenvolvimento das questões ligadas à Alfabetização Científica.

Os resultados da análise sugerem que ao preparar cada vez mais os profissionais responsáveis pelo processo de aprendizagem dos alunos será possível modificar não somente suas práticas pedagógicas, mas também superar currículos fragmentados e baseados na exclusiva reprodução de conceitos sobre as determinadas áreas do saber.

Nesse sentido, o desenvolvimento de uma cultura científica capaz de formar o educando para o exercício de seu papel como ator social está diretamente ligado aos processos de formação e capacitação dos professores, revelando que esta é uma área ainda em desenvolvimento. 


\section{REFERÊNCIAS}

BAZZO, Walter Antonio. Ciência, Tecnologia e Sociedade: e o contexto da educação tecnológica. Florianópolis: Editora UFSC, 1998.

BRASIL. Secretaria de Educação Fundamental. Parâmetros curriculares nacionais: Ciências naturais. Brasília: MEC/SEF, 1997.

BRITO, Liliane Oliveira. Ensino de Ciências por investigação: uma estratégia pedagógica para promoção da alfabetização científica nos primeiros anos do ensino fundamental. Maceió: UFAL, 2014. Dissertação Mestrado, Universidade Federal de Alagoas, Programa de Pós-Graduação em Ensino de Ciências e Matemática, 2014.

CACHAPUZ, António; GIL-PÉREZ, Daniel; CARVALHO, Anna Maria Pessoa; PRAIA, João; VILCHES, Amparo. A necessária renovação do ensino das Ciências. São Paulo: Cortez, 2005.

CARVALHO, Anna Maria; VANUCCHI, André Infantosi; BARROS, Marcelo Alves; GONÇALVES, Maria Elisa Resende; REY, Renato Casal. Ciências no Ensino Fundamental: o conhecimento físico. São Paulo: Scipione, 1998.

CHASSOT, Antonio. Alfabetização científica: uma possibilidade para a inclusão social. Revista Brasileira de Educação, São Paulo, v. 23, n. 22, p. 89-100, 2003. Disponível em: <http://www.scielo.br/pdf/rbedu/n22/n22a09.pdf> Acesso em: 8set15.

DELIZOICOV, Demétrio; ANGOTTI, José André. Metodologia do Ensino de Ciências. São Paulo/BRA: Cortez, 2000.

DELIZOICOV, Demétrio; ANGOTTI, José André; PERNAMBUCO, Marta Maria. Ensino de ciências: fundamentos e métodos. 3 ed. São Paulo: Cortez, 2009.

LONGHINI, Marcos Daniel. O conhecimento do conteúdo científico e a formação do professor das séries iniciais do ensino fundamental. Investigações em Ensino de Ciências, v. 13, n. 2, p.241253, 2008. Disponível em: < http://www.if.ufrgs.br/ienci/artigos/Artigo_ID184/v13_n2_a2008.pdf>. Acesso em: 13 mai16.

LORENZETTI, Leonir; DELIZOICOV, Demétrio. Alfabetização científica no contexto das séries inicias. Ensaio - Pesquisa em Educação em Ciências, v. 3, n. 1, jun. 2001. Disponível em: <http://www.fae.ufmg.br/ensaio/v3_n1/leonir.PDF> Acesso em 14ago17.

LORENZETTI, Leonir. Alfabetização científica no contexto das séries iniciais. Florianópolis: UFSC, 2000. Dissertação (Mestrado em Educação), Universidade Federal de Santa Catarina,2000.

RODRIGUES, Margarete do Rocio. Conceitos de física para crianças: uma proposta para as séries iniciais. Ponta Grossa: UTFPR, 2010. Dissertação (Mestrado em Ensino de Ciência e Tecnologia) Programa de Pós-Graduação em Ensino de Ciência e Tecnologia, Universidade Tecnológica Federal do Paraná. 2010.

ROSA, Cleci Werner; PEREZ, Carlos Ariel Samudio; DRUM, Carla. Ensino de física nas séries iniciais: concepções da prática docente. Investigações em Ensino de Ciências, v. 12, n. 3, p.357-368, 2007. Disponível em < http://www.if.ufrgs.br/public/ensino/vol12/n3/v12_n3_a4.htm>>. Acesso em 31maio16.

VALE, José Misael Ferreira. Educação científica e sociedade. In: NARDI, Roberto (org). Questões atuais no ensino de Ciências. $2^{a}$ ed. São Paulo: Escrituras, 2009.

VIECHENESKI, Juliana Pinto; CARLETTO, Marcia. Por que e para quê ensinar ciências para crianças. Revista Brasileira de Ensino de Ciência e Tecnologia, v. 6, n. 2, 2013. Disponível em: <http://revistas.utfpr.edu.br/pg/index.php/rbect/article/view/1638>. Acesso em: 19 maio 2016. 